\title{
Reflections on duty of care to guarantee elderly
}

\begin{abstract}
Reflective article come from $\mathrm{r}$ evision integrative about the construct 'care duty of the elder. "From the VHL Portal databases Virtual Health Library and Science Direct, various types of documents were recovered and analyzed. To do so, the following keywords were used: elderly and duty of care in the Portuguese and Spanish languages. We selected the studies published in the last 5 years, which were available in full. The research was carried out by three researchers, blindly and isolated, followed by subsequent cross-checking of the findings. The findings were grouped by similarities and differences and described considering the theoretical and legal aspects of the guarantee of the duty to care for the elderly in Brazil and the absence Effectiveness of this right.
\end{abstract}

Volume 2 Issue I - 2017

\author{
Ulissea De Oliveira Duarte,' Raimunda \\ Hermelinda Maia Macena, ${ }^{2}$ Sealtiel Duarte \\ de Oliveira ${ }^{3}$ \\ 'Assistant Professor, State University of Rio Grande do Norte, \\ Brazil \\ ${ }^{2}$ Department of Physical Therapy, Federal University of Ceará, \\ Brazil \\ ${ }^{3}$ Public Defender of Final Admission - General Public Defender \\ of The State of Ceará and Assistant ProfessorlV of the State, \\ University of Rio Grande do Norte, Brazil
}

Correspondence: Raimunda Hermelinda Maia Macena,
Department de Fisioterapia, Universidade Federal do Ceará,
Brazil,Tel +55 85 3366-88I2, Fax +55 85 3366-8004,
Email lindamacena@gmail.com

Received: June 26, 2017 | Published: August 18, 2017

\section{Introduction}

Human aging can be understood as a universal, dynamic and irreversible process, influenced by biological, social, psychological and environmental factors. ${ }^{1,2}$ The proportion of the elderly is growing faster than any other age group in Brazil and the world. It is estimated that growth by 2025 will be 1.2 billion elderly people worldwide. ${ }^{3,4}$

Brazil is experiencing a demographic transition process, in particular the elderly population as the age group the fastest growing, with an increase of chronic conditions of illness, together with the coexistence of infectious diseases and external causes, generating social and demographic indexes of the First World, though with systems and institutions inherited from another socio-political context. ${ }^{2-6}$ The more conservative projections indicate that, by 2020 , Brazil will be the sixth country in the world in the number of elderly, with a contingent of more than 30 million people.,

However, international principles stemming from international treaties make it possible for the individual to demand from the State the realization of basic rights for survival., $2,8,9$ The promulgation of the Brazilian Federal Constitution of 1988 (CF) began a new social phase, in which the guarantee of citizen rights becomes the focus of concentration. ${ }^{9}$

Historically, aging was emphasized as a phenomenon related to the physical process and restricted to the family sphere. The quantitative increase of this group, as stated in previous lines, makes aging a social issue and is currently one of the main political challenges, as it is essential to define new spaces in the various social structures for older people and to reinforce the responsibility of the elderly state. ${ }^{10}$ In view of this, international principles, derived from international treaties, enable the individual to demand from the State the realization of basic rights for survival. , $, 8,9^{2}$

\section{Method}

The research was performed by THREE researchers, blindly and solated, of posterior crossing of the findings. Initially it was held integrative thematic review from data obtained on the Portal VHL Virtual Health Library brings together 14 bibliographic databases in health sciences and Science Direct which are available from Elsevier publications and other scientific publishers, covering the areas of Life Sciences, Health Sciences, Agricultural Sciences, Exact and Earth Sciences, Engineering, Social Sciences, Humanities and Arts and Letters .

The VHL portal and Science Direct have free and open access. Bibliographical databases have references to articles and scientific documents, with or without a summary. Search guided by the following thematic issues were carried out: What information available on ensuring elderly duty of care? As inclusion criteria were selected studies (articles or books), written in Portuguese or Spanish, made available full access via online; And as exclusion criteria, content not related to the research question; Incoherent title with the object of study carried out, those that were indexed in more than one database and low methodological quality, such as important methodological information absent, presence of bias, among others.

To do so, the following keywords were used: elderly and duty of care in the Portuguese and Spanish languages. We selected the studies published in the last 5 years, which were available in full. The research was performed by two researchers, blindly and isolated, followed by subsequent cross-checking of the findings.

Initially, the titles and abstracts of the articles were read, in order to identify the references that fit the pre-established criteria. After strenuous reading of the studies, it was possible to identify aspects related to the guarantee of the duty of care with elderly people existing in the current scientific literature. In parallel, this information was cross-checked with the categories from the thematic categories obtained with the interviews conducted for the structuring of contents and thematic organization of educational technology in the light-hard modality.

\section{Results}

Aging is a progressive process of decreasing the functional 
reserve called senescence, while senility is the development of the pathological condition due to emotional stress or other factors of illness. ${ }^{11}$ Therefore, the greater the degree of commitment, quality, resources, management and monitoring of national, regional and local programs of prevention and care for the elderly, the greater the chances of minimizing the fragility of the elderly and their consequences. ${ }^{12,13}$

Thus, the addition of life is an ambition of every community. However, it will only be a true acquisition when adding quality and guarantee of rights to the years of life., ${ }^{2,7}$ At the international level, the question of the elderly is debated, preliminarily, in the United Nations in the 1970s, and is the subject of discussion by the UN General Assembly in which it calls for a World Assembly on aging, warning the countries of the need to protect the rights and welfare of the elderly. ${ }^{1}$

However, only in 1982, in Vienna, began the multilateral discussions on aging, with the holding of the first International Assembly on Aging, which culminated in the drafting of the Vienna Plan of Action on Aging. Considered the first international instrument on aging, this plan addressed specific public policies for health, nutrition, housing, environment, family and social welfare. ${ }^{14}$

The II Assembly prepared the International Plan of Action for Aging (PAIE) by the representatives of the member countries, containing guidelines for the elaboration and establishment of specific policies for the elderly. The PAIE consists of a Political Declaration containing 19 articles expressing responses to the challenges posed by the aging population.

The PIAE recommendations focus on three priority areas: 1) how to put population aging on the development agenda; 2) singular and global importance of health; 3 ) how to develop environmental policies (both physically and socially) that meet the needs of individuals and aging societies. In each of these areas of action, the PIAE prioritizes issues of gender and social inequality. ${ }^{15}$

This PAIA paid particular attention to the situation of developing countries and defined as central themes the realization of all human rights and fundamental freedoms of the elderly, their civil and political rights and the elimination of all forms of violence and discrimination against the person of age. ${ }^{14}$ It should be noted that the Global Plan of Action on Aging, the Charter of Principles for the Elderly as well as the PAIE are normative instruments and principles that do not impose obligations, that is, each State has the independence to adhere to it or not.

In Brazil, the promulgation of the Federal Constitution of 1988 (CF) began a new social phase, in which the guarantee of citizen rights becomes the focus of concentration. ${ }^{9}$ Thus, the Brazilian legal system, in the Constitution, provides for the guarantee of rights and principles related to the dignity of the human being are those related to the rights to equality, life, health, as well as social rights that cover education, health, Work, housing, leisure, security, social security, among others. ${ }^{8}$ In addition to the Federal Constitution of 1988, Brazil developed Law No. 8,842 / 1994, which deals with the National Policy on the Elderly ${ }^{16}$ and the Elderly Statute, which define the elderly as people aged 60 and over, adopting a concept of aging Active that expresses the maintenance of functional capacity; Assistance to the health needs of the elderly; Rehabilitation of impaired functional capacity; Training of specialized human resources; Support for the development of informal care and research and the promotion of healthy aging. ${ }^{17}$
According to the previous topic, the absence of the "duty of care" for the elderly is a hypothesis of an unlawful act, according to the Brazilian Civil Code, and consequently the practice of it constitutes a form of violence against the elderly. ${ }^{2,9,18,19}$ In addition these types of violence against the elderly also have protection in the criminal sphere, since it constitutes a crime according to the status of the elderly from Articles 96 to 108 of the said statute. , $13,16,19,20^{2}$

However, before any legal apparatus there is still a lack of knowledge of the rights of the elderly and consequent disregard for the citizens of the elderly, added to the precariousness of public policies and investments to solve the specific demands of this segment of the population. ${ }^{6,7,9}$ The most conservative projections indicate that, by 2020 , Brazil will be the sixth country in the world in the number of elderly, with a contingent of more than 30 million people., 3,7

Recognizing that it is the duty of the family, the State and society to support the elderly, ensuring their participation in the community, defending their dignity and well-being and guaranteeing them the right to life ${ }^{8}$ there is an immense challenge in Brazilian society In relation to the effectiveness of the rights of the elderly, in specific to the duty of care. ${ }^{3,9,20,21}$

In this way, it is the responsibility of society and the State to create diversified, secure and accessible social ties and facilities for the elderly, to guarantee and foster their civic participation at all levels of decision-making. Promoting social life is a collective and individual responsibility. The social support network must correspond to an affective and supportive investment and is certainly a decisive capital throughout life and also during aging. ${ }^{9,22,23}$

\section{Final considerations}

Therefore, due to the lack of knowledge of the rights and guarantees of the elderly, it is necessary for professionals who work in the protection and shelter network to perceive the elderly must act by observing the multi-causality of the processes in several areas, such as linked to physical, mental or social factors, Individual or collective, contextualizing the individual in their environment, as well as being focused on the creation of new values in an interdisciplinary way. ${ }^{9,18}$ In this sense, multiprofessional teamwork requires an integrated action, grounded in an interdisciplinary model among professionals in the area of Health, Law, Social Assistance and entities focused on the defense of the rights and protection of the elderly.

\section{Acknowledgements}

None.

\section{Conflict of interest}

Author declares there is no conflict of interest in publishing the article.

\section{References}

1. Dantas F, Souza AL. International guidelines and policies for the elderly in Brazil: the ideology of active aging. Journal of Public Policy. 2011;14(1).

2. Veras RP. International Experiences and Trends of Care Models for the Elderly International Experiences and Trends in Health Care Models for the Elderly. Cien Saude Colet. 2012;17(1):231-238.

3. Branches LR. The demographic explosion of the elderly in Brazil: a public health issue. Rev Gerontology. 2015;3-8. 
4. Fabrício SCC, Rodrigues RAP. Review of the literature on fragility and its relation with aging. Northeast Network Nursing Journal. 2016;9(2).

5. Fechine BRA, Trompieri N. The aging process: the main changes that occur with the elderly over the years. Inter Science Place. 2015;1(20).

6. Veras R. Forum. Population aging and PNAD health information: contemporary demands and challenges. Introduction. Cadernos de Saúde Pública. 2007;23(10):2463-2466.

7. Veras R. Contemporary population aging: demands, challenges and innovations. Journal of Public Health. 2009;43(3):548-254.

8. Federal C. plateau Gov Br. Access in 7. 1988.

9. Santin JR, Borowski MZ. The elderly and the constitutional principle of human dignity. Revista Brasileira de Ciências do Agrocimento Humano. $2008 ; 5(1)$

10. International Guidelines for Aging and its Consequences on the Concept of Old Age. Meeting of the Brazilian Association of Population Studies. 2002;12:1-10.

11. Ciosak SI, Braz E, MFBNA Coast, et al. Senescence and senility: a new paradigm in basic health care. Rev Esc Enferm USP. 2011;45(spe2):1763-1768.

12. Peace AA, Santos BRLd, Eidt OR. Vulnerability and aging in the context of health. Acta Paul Enferm. 2006;19(3):338-342.

13. Pavarini SCI, Mendiondo MSZd, Barham EJ, et al. The art of caring for the elderly: gerontology as a profession. Texto Contexto-enferm, Florianópolis. 2005;14(3):398-402.

14. Notari MHdA, Fragoso MHJ. The insertion of Brazil into the international human rights policy of the elderly. GV Law Journal. 2011;259-276.
15. Camarano AA, Pasinato MT. Population aging on the public policy agenda. The new Brazilian elderly: far beyond the. 2004;60(1):253-292.

16. Provides for the National Policy of the Elderly. Creates the National Council for the Elderly and provides other measures. Official Journal of the Union, Brazil; 1994.

17. Dias JA, Arreguy SC, Pinto PF, et al. Being old and the aging process: perceived health. Esc Anna Nery. 2011;15(2):372-379.

18. Gerlack LF, Moreira LB, Serbim AK, et al. Elderly health: multiprofessional residence as a transformative instrument of care. Science and Health. 2010;2(2):104-108.

19. Viegas CMdAR, Barros MF. Abandonment of Affective Reversals: Abandonment of the Elderly and Violation of Duty of Care by Part of Offspring. Cadernos do Programa de Pós-Graduação em Direito. 2016;11(3).

20. Fernandes MTO, Soares SM. The development of public policies of attention to the elderly in Brazil. Rev Esc Enferm USP. 2012;46(6):1494-1502.

21. Menezes RLd, Bachion MM, Souza JTd, et al. Longitudinal study of the multidimensional aspects of the health of the institutionalized elderly. Rev Bras Geriatr Gerontol. 2011;14(3):485-496.

22. Paúl C. Active aging and social support networks. Sociology. 2005;15:275-287.

23. Brito FJCM, Ferreira VR. Fundamental Right to Health and Individual Protection: Reading this Constitutional Right to the Light of Equal Liberalism. Conpedi Law Review. 2016;1(2):274-290. 